\title{
Patients Come Clean: How Patient Factors and the Bowel Preparation Experience Influence Bowel Preparation Quality
}

\author{
Joshua M Anderson ${ }^{1}$, Lauren Stemboroski ${ }^{2}$, Petra Aldridge ${ }^{3}$, Asim Shuja ${ }^{1}$, Miguel Malespin ${ }^{1}$ and Silvio W de Melo \\ $\mathrm{Jr}^{1 *}$
}

${ }^{1}$ Division of Gastroenterology, University of Florida College of Medicine and UF Health, Florida

${ }^{2}$ Department of Internal Medicine, University of Florida College of Medicine and UF Health, Florida

${ }^{3}$ Center for Health Equity and Quality Research, University of Florida College of Medicine, Florida

Received: 诽 June 14, 2018; Published: 韭July 18, 2018

*Corresponding author: Silvio W de Melo Jr, Division of Gastroenterology, University of Florida College of Medicine and UF Health, Florida, 4555 Emerson St, Suite 300, Jacksonville, Florida.

\begin{abstract}
Suboptimal bowel preparation (prep) leads to shorter interval colonoscopy time, missed lesions, and increased healthcare costs. The aim of this study was to assess whether the patient's experience was associated with bowel prep quality. A single center retrospective analysis was performed of 200 patients with documented adequate and suboptimal bowel prep who had undergone colonoscopy and agreed to be surveyed were included in the study. Demographic information, baseline characteristics, bowel prep scores, colonoscopy findings, and survey responses were analyzed. There was a significant relationship between prep quality and the following: "how did you perceive bowel prep went?" "were you compliant with recommended clear liquid diet?" "did you have any nausea or vomiting while taking bowel prep?" and "was your stool clear prior to procedure?". The logistic regression model selection found the best fit model contained a documented history of chronic constipation, prior inadequate bowel prep, patient's perception of how well the bowel prep went, and reported stool clarity. The odds of suboptimal preparation are 5.5 times higher for those with a history of chronic constipation than those without; 2.8 times higher for those with a history of poor prep; 9.5 times higher for those who perceived prep did not go well, 6.6 times higher for those who did not report clear stool, and 3.9 times higher for males. Patients who perceived their bowel prep went well; followed a clear liquid diet; denied nausea and vomiting and reported clear stool had more adequate bowel preparation quality.
\end{abstract}

Keywords: Colonoscopy; Bowel Preparation; Quality; Patient experience

Abbreviations: CRC: Colorectal Cancer; TBBPS: Total Boston Bowel Preparation Scale Score; IRB: Institutional Review Board; BMI: Body Mass Index; ASA: American Society of Anesthesiologists; NP: Nurse Practitioner; PA: Physician's Assistant; PCP: Primary Care Provider; PEG: Polyethylene Glycol

\section{Introduction}

Colonoscopy is the preferred technique for colorectal cancer (CRC) screening and diagnosing disorders of the lower gastrointestinal (GI) track [1]. Adequate bowel preparation is essential for identification of colonic polyps and malignant lesions [2]. Although colonoscopy was initially billed as being a procedure that was "easy to prepare for" shortly after its introduction in the early 1970s, the burden of suboptimal bowel preparation persists despite advancement in purgative techniques [1,3]. The portion of inadequate bowel prep has been shown to be as high as $30 \%$ of colonoscopies in large safety net health care systems [4]. In addition to potentially missing significant precancerous and cancerous lesions, inadequate bowel preparation also increases healthcare expense and lost productivity as it requires colonoscopy be repeated at shorter intervals with varying degrees of inadequacy [5-6].
Previous research suggests that gender, marital status, compliance with bowel prep and dietary restrictions prior to colonoscopy, split dose bowel preparation, and runaway time all play a role in quality of bowel preparation [7]. The medical field recently has focused on patient experience as a quality metric, affecting many aspects of practice including reimbursement [8]. Hatoum et al. [9] showed that patient-reported satisfaction of bowel-cleansing preparations is predictive of higher future acceptability of future procedures but did not show an associated improvement in bowel prep quality. The aim of our study was to assess whether the patient experience was associated with bowel prep quality. We also sought to identify if there were aspects of the pre-procedural clinical encounter and bowel preparation education process that were associated with suboptimal bowel prep in order to improve the process for future encounters. 


\section{Methods}

\section{Study Design}

We performed a single center retrospective analysis of patients who had recently undergone outpatient colonoscopy at an urban safety net hospital. The study surveyed 200 patients who had undergone outpatient colonoscopies for various indications from May 2016 to July 2016, 100 of which had documented adequate and 100 who had documented suboptimal bowel preparation. Patients were identified using the endoscopic procedure documentation software Provation ${ }^{\circledR}$ MD. The most recent patients from each group who had completed colonoscopic evaluation were contacted and asked to participate in a phone survey. Exclusion criteria included procedures performed on patients younger than 18 years old, hospitalized patients, an inability to contact patients, procedures that were terminated for reasons unrelated to bowel preparation adequacy, and patients who declined to participate in the study. Documentation of bowel prep adequacy was done with either subjective qualifiers documented by the endoscopist known as the Aronchick scale or utilizing the Total Boston Bowel Preparation Scale Score (TBBPS) [10,11]. Colonoscopies were considered adequate if they had the following qualifiers documented; "adequate", "excellent", and "good" or those with TBBPS $\geq 5$. "Fair", "poor", "inadequate", and those with TBBPS $<5$ documented were considered suboptimal bowel preparation. The most commonly used preparations included sodium phosphate (Suprep ${ }^{\circledR}$ bowel prep kit) and 4L polyethylene glycol 3350 solution (GoLYTELY®). The patients were instructed to take their bowel preparation in a split dose formulation.

\section{Data Collection}

Demographic data collected included patient's age, gender, height, weight, body mass index (BMI), ethnicity, marital status, American Society of Anesthesiologists (ASA) classification score, and insurance carrier. The referring provider seen during the pre-procedural clinic visit, type of bowel prep used, documented use of additional laxatives, opiate analgesics, and history of chronic constipation was also collected. Procedural data collected included indication, bowel prep score, significant complications, location performed, and time of day the procedure was performed. Procedural findings collected included the presence of adenomas, advanced adenomas ( $>1 \mathrm{~cm}$, villous histological component), and colon cancer. Endoscopic suites where procedures were performed were dedicated to either endoscopist directed conscious sedation or anesthetist-directed anesthesia. The time the procedure was performed was subdivided into morning and afternoon categories. The insurance carrier was broken down into four categories based on who was the primary payer; underinsured, Medicaid, Federal, and Commercial insurance. The underinsured group includes those patients receiving charity care or are covered through "City Contract" a safety net program to provide care to local residents who are underserved and otherwise uninsured [12]. The referring provider was considered the medical provider who evaluated the patient during the pre-procedural clinic visit and ordered the colonoscopy. The category was subdivided into GI fellow physician,
GI attending physician, GI specialized nurse practitioner (NP) or physician's assistant (PA), and primary care provider (PCP).

\section{Phone Survey}

Patients who met the inclusion criteria were contacted and read a standard dialogue informing them about the study and verbal consent was requested to participate. Those who elected to proceed were asked 15 questions regarding their bowel preparation experience. A telephone interpreter was used for those with a language barrier.

\section{Statistical Analysis}

Continuous variables were summarized using means \pm standard deviations, and analyzed using Wilcoxon's rank sum test (a non-parametric test). Categorical variables were described using counts and percentages, and analyzed using Fisher's exact tests. The best subset selection method was performed to assess the best predictive model of adequate prep quality. This method finds the best models containing one variable, two variables, three variables, and so on, up to the single model containing all of the independent variables. The criterion used to determine the "best" subset is based on the global score chi-square statistic. For two different models, each having the same number of explanatory variables, the model with the higher score chi-square statistic is considered to be better. The Akaike Information Criterion (AIC for each model was also compared, the model with the lower AIC is considered better. All analyses were performed using SAS $®$ Version 9.4 for Windows.

\section{Ethics}

This study was approved by the institutional review board (IRB) at the University of Florida-Jacksonville (IRB UFJ 2015-168). The IRB approved a waiver of consent for medical record review and a modified verbal consent for the phone survey portion. The study protocol was revised and updated January 2017.

\section{Results}

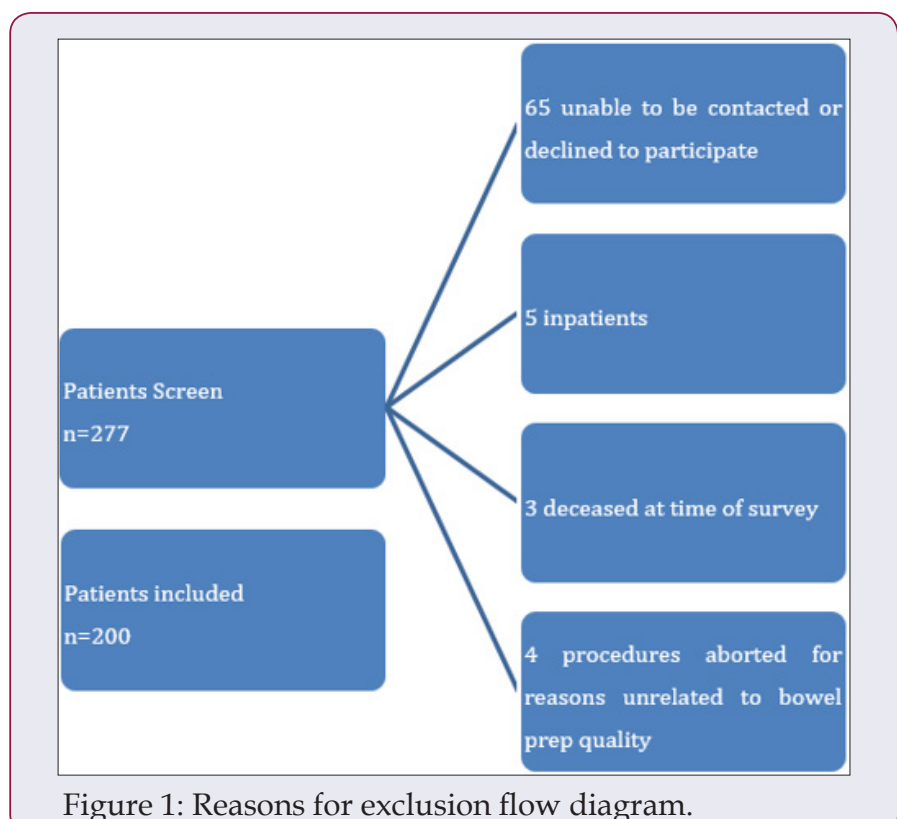


We screened 277 patients who had undergone colonoscopy. Seventy-seven patients were excluded from analysis (Figure 1). Three patients were deceased at the time of the phone survey from causes unrelated to the procedure or sedation. One of those patients Table 1: Demographics/baseline characteristics.

\begin{tabular}{|c|c|c|c|c|c|}
\hline Variable & Category & Adequate & Inadequate & Overall & P-Value \\
\hline \multirow[t]{2}{*}{ Gender } & Female & $64(55.2)$ & $52(44.8)$ & $116(58)$ & 0.115 \\
\hline & Male & $36(42.9)$ & $48(57.1)$ & $84(42)$ & \\
\hline \multirow[t]{3}{*}{ Race } & Black & $66(56.9)$ & $50(43.1)$ & $116(58)$ & 0.040 \\
\hline & Other & $6(54.5)$ & $5(45.5)$ & $11(5.5)$ & \\
\hline & White & $28(38.4)$ & $45(61.6)$ & $73(36.5)$ & \\
\hline \multirow[t]{4}{*}{ Insurance } & Commercial & $20(41.7)$ & $28(58.3)$ & $48(24.2)$ & 0.424 \\
\hline & Federal & $19(57.6)$ & $14(42.4)$ & $33(16.7)$ & \\
\hline & Medicaid & $42(54.5)$ & $35(45.5)$ & 77 (38.9) & \\
\hline & Under Insured & $19(47.5)$ & $21(52.5)$ & $40(20.2)$ & \\
\hline \multirow[t]{2}{*}{ Location/Sedation } & Moderate sedation suites & $11(31.4)$ & $24(68.6)$ & $35(17.5)$ & 0.025 \\
\hline & MAC/General sedation suites & $89(53.9)$ & $76(46.1)$ & $165(82.5)$ & \\
\hline \multirow[t]{5}{*}{ Marital status } & Divorced/Legally Separated & $38(50.7)$ & $37(49.3)$ & $75(37.5)$ & 0.050 \\
\hline & Married/Significant Other & $25(42.4)$ & $34(57.6)$ & $59(29.5)$ & \\
\hline & Other/Unknown & $3(75)$ & $1(25)$ & $4(2)$ & \\
\hline & Single & $30(63.8)$ & $17(36.2)$ & $47(23.5)$ & \\
\hline & Widowed & $4(26.7)$ & $11(73.3)$ & $15(7.5)$ & \\
\hline \multirow[t]{2}{*}{ Obese $(\mathrm{BMI}>30)$} & No & $43(51.8)$ & $40(48.2)$ & $83(41.5)$ & 0.774 \\
\hline & Yes & $57(48.7)$ & $60(51.3)$ & $117(58.5)$ & \\
\hline \multirow[t]{2}{*}{ Morbid Obesity, BMI $>40$} & No & $87(53)$ & $77(47)$ & $164(82)$ & 0.097 \\
\hline & Yes & $13(36.1)$ & $23(63.9)$ & $36(18)$ & \\
\hline \multirow[t]{2}{*}{ History of Chronic constipation } & No & $83(61)$ & $53(39)$ & $136(68)$ & $<0.001$ \\
\hline & Yes & $17(26.6)$ & $47(73.4)$ & $64(32)$ & \\
\hline \multirow[t]{2}{*}{ Opiates } & No & $67(58.3)$ & $48(41.7)$ & $115(57.5)$ & 0.010 \\
\hline & Yes & $33(38.8)$ & $52(61.2)$ & $85(42.5)$ & \\
\hline \multirow[t]{2}{*}{$\begin{array}{l}\text { History of prior poor/ inadequate bowel } \\
\text { prep }\end{array}$} & No & $82(55)$ & $67(45)$ & $149(74.5)$ & 0.023 \\
\hline & Yes & $18(35.3)$ & $33(64.7)$ & $51(25.5)$ & \\
\hline \multirow[t]{3}{*}{ ASA Class } & 2 & $76(60.3)$ & $50(39.7)$ & $126(63.4)$ & $<0.001$ \\
\hline & 3 & $22(32.4)$ & $46(67.7)$ & $68(34.5)$ & \\
\hline & 4 & $2(66.7)$ & $1(33.3)$ & $3(1.5)$ & \\
\hline \multirow[t]{4}{*}{ Referring Provider } & GI Fellow & $10(55.6)$ & $8(44.4)$ & $18(9)$ & 0.879 \\
\hline & GI Attending & $7(58.3)$ & $5(41.7)$ & $12(6)$ & \\
\hline & GI NP/PA & $64(48.5)$ & $68(51.5)$ & $132(66)$ & \\
\hline & PCP & $19(50)$ & $19(50)$ & $38(19)$ & \\
\hline \multirow[t]{3}{*}{ Indication } & diagnostic/Therapeutic & $27(52.9)$ & $24(47.1)$ & $51(25.5)$ & 0.902 \\
\hline & screening & $46(48.9)$ & $48(51.1)$ & $94(47)$ & \\
\hline & surveillance & $27(49.1)$ & $28(50.9)$ & $55(27.5)$ & \\
\hline \multicolumn{6}{|c|}{ Data for Adequate and Inadequate presented as n (\% category) } \\
\hline \multicolumn{6}{|c|}{ Data for Overall presented as n (\% variable) } \\
\hline \multicolumn{6}{|c|}{ All tests done using Fisher's Exact Test } \\
\hline
\end{tabular}

had succumbed to a colorectal cancer that had been diagnosed during their colonoscopy. 200 patients were included in the study. 100 of those patients had documented adequate bowel preparation and 100 had documented suboptimal bowel preparation. 
The baseline characteristics of the participants and their associations with bowel prep adequacy for categorical variables are shown in Table 1. Fifty-eight percent of the study population was female, 58\% were African American, 59\% had a BMI >30, and over $50 \%$ were either funded by Medicaid or otherwise underinsured. There was a significant relationship between suboptimal prep quality and the following: white race $(\mathrm{p}=0.04)$, anesthetist-directed sedation $(p=0.025)$, a history of chronic constipation $(p<0.001)$, documented opiate use $(\mathrm{p}=0.01)$, prior inadequate bowel prep $(\mathrm{p}=0.023)$, and higher ASA Class $(\mathrm{p}<0.001)$. There was no significant difference of bowel prep quality amongst the different types of provider assessing and educating the patient in the pre-procedure clinic visit, $\mathrm{p}$-value $=0.879$. Weight was associated with higher risk of suboptimal bowel prep (Table 2). The average weight of patients with suboptimal bowel prep was $94.9 \mathrm{~kg}$ compared to $88.0 \mathrm{~kg}$ for those with adequate bowel prep $(\mathrm{p}=0.041)$. The number of days from the time the patient was seen in clinic to when the procedure was performed also was associated with bowel preparation adequacy as those with suboptimal bowel preparation waited slightly more than 2 weeks longer for their procedure than their adequate prep counterparts, an average of 70.5 days compared to 55.7 days respectively $(\mathrm{p}=0.01)$.

Table 2: Demographic/Baseline Characteristics -Continuous Variables.

\begin{tabular}{|c|c|c|c|c|c|c|c|c|c|}
\hline Variable & Group & $\mathbf{N}$ & Mean & Std Dev & Min & Median & Max & IQR & P-Value \\
\hline \multirow[t]{2}{*}{ Age } & Inadequate & 100 & 58.2 & 9.1 & 22 & 59 & 82 & 11.5 & 0.974 \\
\hline & Adequate & 100 & 58.4 & 9.9 & 22 & 58 & 84 & 12.5 & \\
\hline \multirow[t]{2}{*}{ BMI } & Inadequate & 100 & 33.4 & 8.4 & 15.0 & 31.5 & 56.7 & 11.4 & 0.087 \\
\hline & Adequate & 100 & 31.1 & 7.2 & 16.3 & 30.6 & 50.6 & 9.8 & \\
\hline \multirow[t]{2}{*}{$\begin{array}{l}\text { \# of days waiting for } \\
\text { procedure }\end{array}$} & Inadequate & 99 & 70.5 & 47.3 & 15.4 & 56.63 & 254.5 & 36.9 & 0.010 \\
\hline & Adequate & 100 & 55.7 & 34.0 & 13.5 & 49.37 & 170.3 & 42 & \\
\hline \multirow[t]{2}{*}{ Height } & Inadequate & 100 & 1.69 & 0.11 & 1.50 & 1.68 & 2.03 & 0.15 & 0.914 \\
\hline & Adequate & 100 & 1.68 & 0.11 & 1.45 & 1.68 & 1.91 & 0.17 & \\
\hline \multirow[t]{2}{*}{ Weight } & Inadequate & 100 & 94.9 & 25.7 & 32.7 & 93.0 & 174.1 & 25.0 & 0.041 \\
\hline & Adequate & 100 & 88.0 & 24.6 & 21.6 & 86.0 & 169.2 & 29.4 & \\
\hline \multicolumn{10}{|c|}{ All tests done using Wilcoxon's Rank Sum Test } \\
\hline
\end{tabular}

Table 3: Procedure information -Prep type and findings.

\begin{tabular}{|c|c|c|c|c|c|}
\hline \multirow[b]{2}{*}{ Variable } & \multirow[b]{2}{*}{ Category } & \multicolumn{2}{|c|}{ Prep Quality } & \multirow[b]{2}{*}{ Overall } & \multirow[b]{2}{*}{ P-Value } \\
\hline & & Adequate & Inadequate & & \\
\hline \multirow[t]{3}{*}{ Type of bowel prep used } & PEG & $88(49.4)$ & $90(50.6)$ & $178(89)$ & 0.646 \\
\hline & Suprep & $12(57.1)$ & $9(42.9)$ & $21(10)$ & \\
\hline & Miralax & $0(0)$ & $1(100)$ & $1(1)$ & \\
\hline \multirow[t]{2}{*}{ Use of additional laxatives } & No & $81(54.0)$ & $69(46.0)$ & $150(75)$ & 0.072 \\
\hline & Yes & $19(38.0)$ & $31(62.0)$ & $50(25)$ & \\
\hline \multirow[t]{2}{*}{ Time started } & $\mathrm{AM}$ & $76(53.9)$ & $65(46.1)$ & $141(70)$ & 0.121 \\
\hline & PM & $24(40.7)$ & $35(59.3)$ & $59(30)$ & \\
\hline \multirow[t]{2}{*}{ Adenomas detected } & No & $52(45.2)$ & $63(54.8)$ & $115(58)$ & 0.152 \\
\hline & Yes & $48(56.5)$ & $37(43.5)$ & $85(42)$ & \\
\hline \multirow[t]{2}{*}{ Advanced adenomas } & No & 87 (48.9) & $91(51.1)$ & $178(89)$ & 0.499 \\
\hline & Yes & $13(59.1)$ & $9(40.9)$ & $22(11)$ & \\
\hline \multirow[t]{2}{*}{ Colon cancer } & No & $99(50.0)$ & $99(50.0)$ & $198(99)$ & 1.000 \\
\hline & Yes & $1(50.0)$ & $1(50.0)$ & $2(1)$ & \\
\hline \multirow[t]{2}{*}{ Complication } & no significant complication & $100(50.3)$ & 99 (49.7) & 199 (99) & 1.000 \\
\hline & significant complication & $0(0)$ & $1(100)$ & $1(1)$ & \\
\hline \multicolumn{6}{|c|}{ Data for Adequate and Inadequate presented as n (\% category) } \\
\hline \multicolumn{6}{|c|}{ Data for Overall presented as n (\% variable) } \\
\hline \multicolumn{6}{|c|}{ All tests done using Fisher's Exact Test } \\
\hline
\end{tabular}

Cite this article: Joshua M A, Lauren S, Petra A, Asim S, Miguel M, et al. Patients Come Clean: How Patient Factors and the Bowel Preparation Experience Influence Bowel Preparation Quality. Biomed J Sci\&Tech Res 7(1)- 2018. BJSTR. MS.ID.001441. D0I: 10.26717/ 
Bowel preparation details, timing of procedure, findings of procedure, and complications were also evaluated (Table 3). In this cohort of patients no significant differences were observed. The type of bowel preparation utilized, the use of additional laxatives did not improve bowel prep adequacy.

Amongst the survey questions, there was a significant relationship between prep quality and the following: "How did you perceive bowel prep went?"; "Were you compliant with recommended clear liquid diet?"; "Did you have any nausea or Table 4: Survey Responses.

\begin{tabular}{|c|c|c|c|c|c|}
\hline & & Prep Quality & & & \\
\hline Variable & Category & Adequate & Inadequate & Overall & P-Value \\
\hline \multirow{2}{*}{$\begin{array}{c}\text { Patient perceived barriers, "How did you perceive bowel prep } \\
\text { went" }\end{array}$} & Not well & $5(11.4)$ & $39(88.6)$ & $44(22.6)$ & $<0.001$ \\
\hline & Well & $92(60.9)$ & $59(39.1)$ & $151(77.4)$ & \\
\hline \multirow{2}{*}{$\begin{array}{l}\text { Were bowel prep timing, method, and dietary modifications } \\
\text { clearly explained to you? }\end{array}$} & No & $4(28.6)$ & $10(71.4)$ & $14(7.2)$ & 0.164 \\
\hline & Yes & $93(51.4)$ & $88(48.6)$ & $181(92.8)$ & \\
\hline \multirow[t]{4}{*}{ Who explained bowel prep? } & Both & $56(47.1)$ & $63(52.9)$ & $119(61)$ & 0.311 \\
\hline & Clinic & $22(55)$ & $18(45)$ & $40(20.5)$ & \\
\hline & GI lab & $15(62.5)$ & $9(37.5)$ & $24(12.3)$ & \\
\hline & No one & $4(33.3)$ & $8(66.7)$ & $12(6.2)$ & \\
\hline \multirow[t]{2}{*}{ Did you receive a handout? } & No & $6(50.0)$ & $6(50.0)$ & $12(6.2)$ & 1.000 \\
\hline & Yes & $91(50.3)$ & $90(49.7)$ & $181(93.8)$ & \\
\hline \multirow[t]{2}{*}{ Was the handout intelligible? } & No & $0(0)$ & $3(100)$ & $3(1.6)$ & 0.121 \\
\hline & Yes & $92(51.1)$ & $88(48.9)$ & $180(98.4)$ & \\
\hline \multirow[t]{2}{*}{ Compliant with clear liquid diet? } & No & $14(28.6)$ & $35(71.4)$ & $49(25)$ & 0.001 \\
\hline & Yes & $83(56.5)$ & $64(43.5)$ & $147(75)$ & \\
\hline \multirow[t]{2}{*}{ Compliance with split dose prep (timing and completion)? } & No & $17(37.8)$ & $28(62.2)$ & $45(22.8)$ & 0.089 \\
\hline & Yes & $81(53.3)$ & $71(46.7)$ & $152(77.2)$ & \\
\hline \multirow[t]{2}{*}{ Did you take multiple days of prep? } & No & $87(50.6)$ & $85(49.4)$ & $172(87.8)$ & 0.828 \\
\hline & Yes & $11(45.8)$ & $13(54.2)$ & $24(12.2)$ & \\
\hline \multirow[t]{2}{*}{ Did you have N/V w/ bowel prep? } & No & $84(53.8)$ & $72(46.2)$ & $156(79.2)$ & 0.034 \\
\hline & Yes & $14(34.1)$ & $27(65.9)$ & $41(20.8)$ & \\
\hline \multirow[t]{2}{*}{ Was your stool clear prior to the procedure? } & No & $8(16.3)$ & $41(83.7)$ & $49(25.1)$ & $<0.001$ \\
\hline & Yes & $90(61.6)$ & $56(38.4)$ & $146(74.9)$ & \\
\hline \multirow[t]{2}{*}{ Would more information would have helped? } & No & $92(52.6)$ & $83(47.4)$ & $175(89.3)$ & 0.063 \\
\hline & Yes & $6(28.6)$ & $15(71.4)$ & $21(10.7)$ & \\
\hline \multirow[t]{2}{*}{ Was there a language barrier? } & No & $94(49.5)$ & $96(50.5)$ & $190(95.0)$ & 0.747 \\
\hline & Yes & $6(60.0)$ & $4(40.0)$ & $10(5.0)$ & \\
\hline \multirow[t]{2}{*}{ medical jargon? } & No & $96(52.2)$ & $88(47.8)$ & $184(93.9)$ & 0.033 \\
\hline & Yes & $2(16.7)$ & $10(83.3)$ & $12(6.1)$ & \\
\hline \multirow[t]{2}{*}{$\begin{array}{l}\text { Did you know who to call if you had questions about bowel } \\
\text { prep? }\end{array}$} & No & $10(41.7)$ & $14(58.3)$ & $24(12.3)$ & 0.514 \\
\hline & Yes & $87(50.9)$ & $84(49.1)$ & $171(87.7)$ & \\
\hline \multirow[t]{2}{*}{$\begin{array}{l}\text { Did you know who to call if you had questions about bowel } \\
\text { prep? }\end{array}$} & No & $6(60)$ & $4(40)$ & $10(5.1)$ & 0.747 \\
\hline & Yes & $96(52.2)$ & $88(47.8)$ & $185(94.9)$ & \\
\hline \multicolumn{6}{|c|}{ Data for Adequate and Inadequate presented as n (\% category) } \\
\hline \multicolumn{6}{|c|}{ Data for Overall presented as n (\% variable) } \\
\hline \multicolumn{6}{|c|}{ All tests done using Fisher's Exact Test } \\
\hline
\end{tabular}

vomiting while taking bowel prep?"; and "Was your stool clear prior to procedure?" (Table 4). Of the 151 respondents who felt that their bowel prep had gone well, $61 \%$ had adequate bowel prep. This is in comparison to $89 \%$ who felt that their bowel prep had gone poorly who had inadequate bowel prep $(\mathrm{P}<0.001)$. Stated compliance with bowel preparation timing, dosing, and completion was not associated with bowel prep adequacy with 53\% of respondents answering "yes" having adequate prep compare to $62 \%$ of those answering "no" having inadequate bowel prep $(\mathrm{P}=0.089)$. 
Table 5: Multivariate logistic regression analysis.

\begin{tabular}{|c|c|c|c|c|c|c|c|}
\hline & & & Wald & & & \multicolumn{2}{c|}{ 95\% Wald Confidence limits } \\
\hline Effect & & DF & Chi-Square & Pr > ChiSq & Odds Ratio Estimates & 2.4 & 12.6 \\
\hline History of chronic constipation & No vs Yes & 1 & 15.846 & $<0.001$ & 5.5 & 1.2 & 6.4 \\
\hline History of poor preparation & No vs Yes & 1 & 5.705 & 0.017 & 2.8 & 3.5 & 29.9 \\
\hline Question 1 & Well vs Not well & 1 & 14.876 & $<0.001$ & 6.6 & 2.4 & 18.0 \\
\hline Question 10 & Yes vs No & 1 & 13.644 & $<0.001$ & 3.9 & 1.8 & 8.5 \\
\hline Gender & Female vs Male & 1 & 11.573 & $<0.001$ & & 2.0 \\
\hline
\end{tabular}

The logistic regression model selection found the best fit model contained history of chronic constipation, history of prior poor bowel prep, patient perceived barriers: "How did you perceive bowel prep went"”, and "Stool clear" (Table 5). The odds of poor prep are 5.5 times higher for those with a history of chronic constipation (95\% CI, 2.4-12.6, $\mathrm{P}<0.001)$; 2.8 times higher for those with a history of poor prep (95\% CI, 1.2-6.4, P=0.017); 9.5 times higher for those perceived prep did not go well (95\% CI, 3-29.9, $\mathrm{P}<0.001), 6.6$ times higher for those who did not report clear stool (95\% CI, 2.4-18, $\mathrm{P}<0.001$ ), and 3.9 times higher for males (95\% CI, 1.8-8.5, $\mathrm{P}<0.001)$.

\section{Discussion}

In this study, we examined the patient's experience with bowel preparation and its relationship with bowel prep quality. We also examined other known risk factors of suboptimal bowel prep in order to assess their effect on the results. Patients who perceived their bowel prep went well and denied nausea or vomiting had improved bowel prep quality. Although the sample size was small, there was no difference in quality among different purgative agents used. This suggests that tolerance of the chosen purgative may be more important than the purgative used. This is consistent with previous observations that showed that poor tolerability resulted in lower quality bowel preparation [13]. Previous studies have also shown that alternatives to PEG may be better tolerated [14]. Therefore, we would recommend providers consider patient's prior experience and expected tolerability when prescribing purgative medication.

Patients who reported compliance with a clear liquid diet also had improved bowel prep quality, suggesting that dietary noncompliance accounts for a portion of the suboptimal bowel preparation burden experienced at our facility and similar populations undergoing elective colonoscopy. Patient's reported compliance with the bowel prep instructions and split dose timing did not appear to be predictive of bowel prep adequacy. However, previous literature has shown reporting a failure to adequately follow instructions is an independent predictor of an inadequate colonic preparation [15]. The same study also hypothesized a significant portion of those reporting compliance with prep instructions may not be compliant. Patient under reporting of compliance may be the cause of the discrepancy between the study findings and literature. There was no significant difference seen in outcome based on the type of provider that saw the patient during the pre-procedure clinical visit. Use of medical jargon and language barrier were also not identified as a barrier to optimal bowel preparation as evidenced by the patient survey results. Patients in the study who had suboptimal prep waited an average of approximately 2 weeks longer from the time they were seen in clinic until there procedure was performed. This indicates pre-procedure waiting times for colonoscopy are more important factors in bowel prep quality than the pre-procedure clinical encounter setting. This additional time is likely also leading to noncompliance as patients forget instructions. This appears to be occurring despite efforts in clinic to combat it as evidenced by $93.8 \%$ of patients recalling reception of a handout, $>98 \%$ of which though it was easy to understand, and reminder calls by the nursing staff routinely the week prior to scheduled colonoscopy appointments. Efforts should be made to minimize waiting times for procedures to help counteract this effect. There was no difference noted in adenoma detection, advanced adenoma detection, or presence of CRC however this is likely secondary to a small sample size.

Several known patient specific risk factors for suboptimal bowel prep were observed to have statistically significant effects on bowel prep quality, including patients with a history of chronic constipation, opioid use, history of prior poor prep, and higher ASA class. Patients who use opiate analgesia and have chronic constipation are thought to have impaired colonic motility which makes preparation difficult. Age did not appear to play a significant factor suggesting that medical comorbidities and physical condition plays a bigger role in ability to prepare for colonoscopy than age alone. This is consistent with previous literature hypothesizing that lower performance status may result in a relative inability to be compliant with prep instructions.15 In the logistic regression analysis men were 3.9 times more likely to have suboptimal bowel prep when compared to women. This may also reflect a problem with compliance as men have previously been shown to be less compliant than women [16]. Patient's weight independent of BMI also was predictive of suboptimal bowel prep. Obesity is a previously reported risk factor for inadequate bowel prep.17 The observation that weight is associated with suboptimal prep is an important one as it illustrates a problem as Americans and citizens of the world become heavier.

The study has several limitations which originate from the study design. Data retrieval was retrospective in nature and relies on data input from a variety of providers including nursing staff, physician 
extenders, GI fellows in training, and GI attending physicians. The phone survey portion of the study is limited by possible recall bias which may influence the results. The generalizability of this study may be limited to similar patient populations and clinical settings. The observations were made in a large academic safety net hospital. The small sample size may have not been adequate to show significant effect from previously described independent risk factors for suboptimal bowel preparation [17].

\section{Conclusion}

The goal of this study was to assess how the pre-procedural patient experience effected bowel prep quality during colonoscopy. We showed patients perception of the preparation process, tolerability of bowel preparation, the length of pre-procedure wait time, and compliance with pre procedure clear liquid diet all have significant effects on bowel prep quality. The study reaffirmed that certain patient-specific factors place patients at higher risk of suboptimal bowel preparation for colonoscopy. Patients with history of chronic constipation, history of poor prep, and male gender had a significantly higher association with inadequate bowel preparation. Efforts should be made to minimize wait times, optimize tolerability of purgative medications, and identify patients at increased risk of suboptimal bowel preparation pre-procedurally in order to target them with additional preparation.

\section{References}

1. Murphy CJ, Jewel Samadder N, Cox K (2015) Outcomes of Next-Day Versus Non-next-Day Colonoscopy After an Initial Inadequate Bowel Preparation. Dig Dis Sci 61(1): 46-52.

2. Rex DK, Petrini JL, Baron TH (2006) Quality indicators for colonoscopy. Am J Gastroenterol 101(4): 873-885.

3. Wolff WI, Shinya H, Geffen A, Ozaktay SZ (1972) Colonofiberoscopy. A new and valuable diagnostic modality. Am J Surg 123(2): 180-184.

4. Kazarian ES, Carreira FS, Toribara NW, Denberg TD (2008) Colonoscopy completion in a large safety net health care system. Clin Gastroenterol Hepatol 6(4): 438-442.

\section{ISSN: 2574-1241}

DOI: 10.26717/BJSTR.2018.07.001441

Silvio W de Melo Jr. Biomed J Sci \& Tech Res

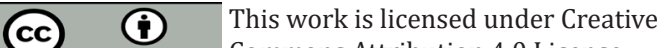

Commons Attribution 4.0 License

Submission Link: https://biomedres.us/submit-manuscript.php
5. Brunner KT, Calderwood AH (2015) Quality in Colonoscopy. Curr Gastroenterol Rep 17(10): 461.

6. Rex DK, Imperiale TF, Latinovich DR, Bratcher LL (2002) Impact of bowel preparation on efficiency and cost of colonoscopy. Am J Gastroenterol 97(7): 1696-1700.

7. Bucci C, Rotondano G, Hassan C (2014) Optimal bowel cleansing for colonoscopy: split the dose! A series of meta-analyses of controlled studies. Gastrointest Endosc 80(4): 566-576.e562.

8. Manary MP, Boulding W, Staelin R, Glickman SW (2013) The patient experience and health outcomes. N Engl J Med 368(3): 201-203.

9. Hatoum HT, Lin SJ, Joseph RE, Dahdal DN (2016) Validation of a Patient Satisfaction Scale in Patients Undergoing Bowel Preparation Prior to Colonoscopy Patient 9(1): 27-34.

10. Calderwood AH, Schroy PC, Lieberman DA, Logan JR, Zurfluh M, et al. (2014) Boston Bowel Preparation Scale scores provide a standardized definition of adequate for describing bowel cleanliness. Gastrointest Endosc 80(2): 269-276.

11. Aronchick CA, Lipshutz WH, Wright SH, Dufrayne F, Bergman G (2000) A novel tableted purgative for colonoscopic preparation: efficacy and safety comparisons with Colyte and Fleet Phospho-Soda. Gastrointest Endosc 52(3): 346-352.

12. https: //ufhealth.org/news/2013/total-care-clinic-ufshandsjacksonville

13. Holt EW, Yimam KK, Ma H, Shaw RE, Sundberg RA, et al. (2014) Patient tolerability of bowel preparation is associated with polyp detection rate during colonoscopy. J Gastrointestin Liver Dis 23(2): 135-140.

14. Hsu CW, Imperiale TF (1998) Meta-analysis and cost comparison of polyethylene glycol lavage versus sodium phosphate for colonoscopy preparation. Gastrointest Endosc 48(3): 276-282.

15. Ness RM, Manam R, Hoen H, Chalasani N (2001) Predictors of inadequate bowel preparation for colonoscopy. Am J Gastroenterol 96(6): 17971802.

16. Vernon SW (1997) Participation in colorectal cancer screening: a review. J Natl Cancer Inst 89(19): 1406-1422.

17. Cheng CL, Liu NJ, Tang JH, et al. (2017) Predictors of Suboptimal Bowel Preparation Using 3-l of Polyethylene Glycol for an Outpatient Colonoscopy: A Prospective Observational Study. Dig Dis Sci 62(2): 345351.

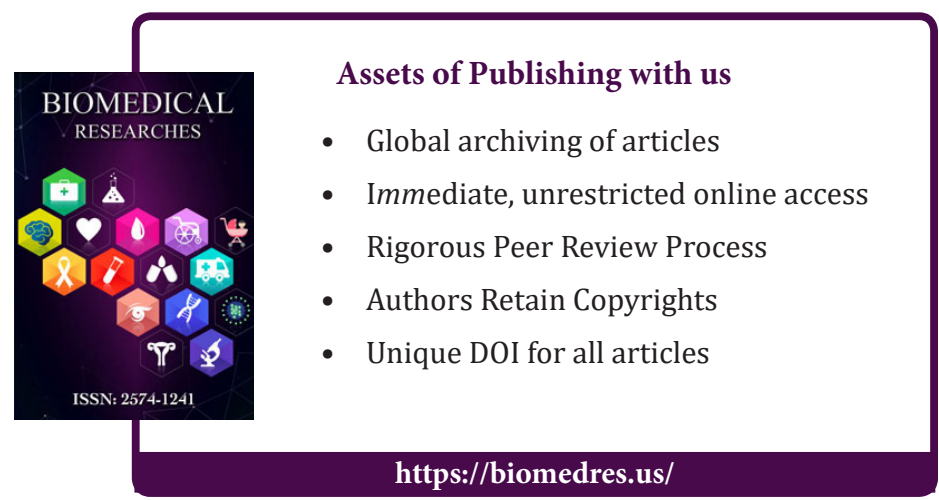

